\title{
Balanço energético para a produção de biodiesel pela cultura da mamona (Ricinus communis L.) ${ }^{1}$
}

\section{Energy balance for biodiesel production by the castor bean crop (Ricinus communis L.)}

\author{
Rodolfo Glauber Chechetto ${ }^{2 *}$, Rubens Siqueira ${ }^{3}$ e Carlos Antonio Gamero ${ }^{4}$
}

\begin{abstract}
Resumo - A cultura da mamona (Ricinus communis L.) adquiriu prestígio ao interesse da indústria pela qualidade de seu óleo e, recentemente, pela busca de novas fontes de energias. O experimento que serviu como base para os dados utilizados nesse trabalho foi realizado na Fazenda Experimental Lageado, FCA - UNESP, no município de Botucatu - SP, no ano de 2008. O objetivo deste trabalho foi avaliar a viabilidade energética da cultura através do balanço e da eficiência energética, desde a implantação até a produção de biodiesel, utilizando parâmetros de consumo operacional no manejo para instalação e manutenção da cultura, colheita e processamento de óleo. As operações de manejo de solo, semeadura e colheita consumiram o total de 266,20 MJ ha ${ }^{-1}$, que juntamente com fertilizantes, agrotóxicos, combustíveis e lubrificantes, mão-de-obra, sementes e processamento industrial totalizaram uma entrada de energia de $56.808,10 \mathrm{MJ} \mathrm{ha}^{-1}$. A produção de energia foi de $72.814,00 \mathrm{MJ} \mathrm{ha}^{-1}$. O setor ainda carece de estudos que contribuiriam para o levantamento de dados e coeficientes energéticos mais específicos. A cultura da mamona foi considerada eficiente, permitindo ganho de $15.983,44 \mathrm{MJ} \mathrm{ha}^{-1}$, equivalente a aproximadamente $415 \mathrm{~L}$ de óleo diesel.
\end{abstract}

Palavras-chave - Eficiência energética. Consumo de energia. Produção de energia.

\begin{abstract}
The castor bean crop (Ricinus communis L.) has acquired prestige due to industries interest in the oil quality and recently for new sources of energy demand. The experiment that served as basis for the data used in this study was conducted at the Lageado Experimental Farm, in Botucatu - SP, 2008. This study aimed to avaluate the crop viability through energy balance and energy efficiency since the implantation until biodiesel production using parameters of consumption in operational management for installation and maintenance of culture harvest and oil production. The soil management operations, sow and harvest consumed the total of $266.20 \mathrm{MJ} \mathrm{ha}^{-1}$, gathering with the fertilizers, pesticides, fuels, lubricants, labor, seed and industrial processing totaled $56,808 \mathrm{MJ} \mathrm{ha}^{-1}$ of energy inputs. The energy production was $72,814.00 \mathrm{MJ} \mathrm{ha}^{-1}$. The industry still lacks studies thal would contribution data collection and more specific energy coefficients. The castor beans cultivation was considered efficient allowing again of $15983.44 \mathrm{MJ} \mathrm{ha}^{-1}$ equivalent to about 415 liters of diesel oil.
\end{abstract}

Keywords - Energy efficiency. Energy consumption. Energy production.

\footnotetext{
* Autor para correspondência

${ }^{1}$ Recebido para publicação em 11/02/2010; aprovado em 13/09/2010

Pesquisa desenvolvida pelo Mestrado no programa de Energia na Agricultura Faculdade de Ciências Agronômicas de Botucatu/UNESP ${ }^{2}$ Programa de Pós-Graduação em Energia na Agricultura, FCA/UNESP, Caixa Postal 237, Botucatu-SP, Brasil, 18.610-307, rgchechetto@fca.unesp.br ${ }^{3}$ Instituto Agronômico do Paraná, IAPAR, Londrina-PR, Brasil, siqueira@iapar.br

${ }^{4}$ Departamento de Engenharia Agrícola, FCA/UNESP, Botucatu-SP, Brasil, gamero@reitoria.unesp.br
} 


\section{Introdução}

A cultura da mamona (Ricinus communis L.) conquistou e vem conquistando espaço no território nacional, principalmente nos estados do Nordeste e Centro-Oeste (CORRÊA et al., 2006; COSTA et al., 2009; MORO, 2008) devido ao interesse pela indústria ricinoquímica e pela busca de fontes energéticas. Embora em regiões brasileiras seja tratada como planta daninha (MACIEL et al., 2007).

No Brasil a mamona é cultivada basicamente em dois sistemas. No tradicional, a colheita é manual, com cultivares de porte médio e alto, difundido entre pequenos produtores. Em sistemas de produção com tecnologias modernas é cultivada em grandes áreas, com colheita mecanizada (MORO, 2008).

A sustentabilidade do sistema agrícola pode ser mensurada de diversas formas. Uma delas é de avaliar um sistema de produção através da análise energética (ALBUQUERQUE et al., 2008a).

São quantificados e identificados todos os insumos utilizados e produzidos, sendo transformados em unidades de energia (SIQUEIRA et al., 1999). As estimativas dos balanços e da eficiência energética são importantes no monitoramento da agricultura ante o uso de energias não renováveis (SIQUEIRA et al., 2008).

A eficiência é medida pelo balanço de energia ou relação output/input, realizada determinando-se a quantidade de energia obtida no produto em relação à utilizada no sistema para produzi-lo (CAMPOS; CAMPOS, 2004). A saída de energia é determinada pela conversão direta do rendimento de produtos em energia (ALBUQUERQUE et al., 2008a).

A entrada de energia se dá pelo trabalho humano, transporte de insumos e produtos, manufatura das máquinas, implementos, insumos agrícolas, entre outros, cuja identificação e quantificação exata são difíceis de serem feitas. Estimativas de energia consumida em um sistema de produção agrícola passaram a ser indispensáveis no planejamento e execução de um sistema de produção (SIQUEIRA et al., 2008).

Das atividades que consomem energia, destacamse a irrigação, a manufatura dos fertilizantes químicos, o uso de combustíveis e a fabricação da maquinaria agrícola. Nos fertilizantes químicos, os nitrogenados destacamse por consumirem maior quantidade de energia na manufatura e serem adicionados em maiores quantidades, quando comparados aos potássicos e fosfatados (FAO, 1980) citados por Albuquerque et al. (2008a).

$\mathrm{Na}$ produção de biodiesel alguns processos são caracterizados, como pirólese e transesterificação com catalisador alcalino ou ácido. O método mais difundido é o segundo com catalisador alcalino (RANESES et al, 1999), este envolve a reação do óleo vegetal com um álcool (metílico ou etílico). O produto dessa reação é um éster, o biodiesel, sendo o principal subproduto a glicerina, utilizada pelas indústrias de plásticos, lubrificantes, cosméticos, fármacos e explosivos. O Brasil é importador de glicerina para atender a essa demanda. Há outros subprodutos como as gomas e a borra que apresentam elevado valor comercial (PLÁ, 2002).

A viscosidade é um problema do biodiesel de mamona, sendo cerca de sete vezes superior a do óleo diesel mineral, resultando em valores fora dos limites permitidos pela portaria da Agencia Nacional do Petróleo, Gás Natural e Bicombustíveis (MAIA et al., 2007).

A avaliação da energia gerada seja para alimentar a população ou como combustível para substituir os derivados de petróleo, permite verificar se o setor agrícola está ou não cumprindo os objetivos de entrada/saída de energia, ou de que forma poderia ser conduzido (SANTOS et al., 2007; URQUIAGA et al., 2005).

O objetivo deste trabalho foi avaliar a viabilidade energética da cultura da mamona, desde sua implantação até a produção de biodiesel.

\section{Material e métodos}

Para se realizar a avaliação energética, qualificouse e quantificou-se todas as operações agrícolas realizadas, bem como as sementes e os insumos utilizados segundo metodologia adaptada por Siqueira et al. (2008).

Os dados para as análises foram obtidos de experimentos conduzidos na Fazenda Experimental Lageado, pertencente à Faculdade de Ciências Agronômicas - UNESP, localizada no município de Botucatu (SP), apresentando como coordenadas geográficas $48^{\circ} 23^{\prime}$ de longitude Oeste e $22^{\circ} 51^{\prime}$ de latitude Sul, com altitude de 740 metros.

Utilizou-se o híbrido Lyra que apresenta ciclo precoce (140 dias), floração com 36 dias após a emergência, $60 \%$ de plantas femininas, rusticidade, altura média de $1,40 \mathrm{~m}$, frutos indeiscentes, boa debulha e produção média de $1.400 \mathrm{~kg} \mathrm{ha}^{-1}$. Além disto, é adequado para colheita mecanizada.

Para uma produção de $1.400 \mathrm{~kg} \mathrm{ha}^{-1}$ de sementes, em geral, a cultura da mamona produz cerca de $770 \mathrm{~kg} \mathrm{ha}^{-1}$ de folhas e $1.946 \mathrm{~kg} \mathrm{ha}^{-1}$ de resíduos (caules, hastes, ramos, etc.).

Segundo Comitre (1993) citado por Campos e Campos (2004), em que formas de entrada de energia 
no agroecossistema como mão-de-obra, sementes e trabalho animal, de origem biológica e óleo diesel, lubrificantes e graxa, estas de origem fóssil, são consideradas do tipo energia direta. Por outro lado, máquinas, implementos, corretivo de solo e adubos químicos foram considerados formas de energia de origem industrial do tipo indireta.

O preparo do solo foi realizado com uma aração e uma gradagem. O cálculo da energia necessária para executar cada operação mecanizada foi realizado pela quantidade de energia correspondente à fabricação dos tratores, equipamentos e combustível, relacionando-a com sua massa, vida econômica, capacidade de trabalho e eficiência operacional de campo (SIQUEIRA et al., 1999).

Considerou-se 12.000 horas como vida econômica dos tratores $(55 \mathrm{~kW}), 5.000$ horas para o arado de discos e a grade de discos e 3.000 horas para a semeadora. A capacidade de campo teórica utilizada foi de $0,525 \mathrm{ha} \mathrm{h}^{-1}$ para o arado de discos; 1,770 ha $\mathrm{h}^{-1}$ para a grade e $1,702 \mathrm{ha} \mathrm{h}^{-1}$ para a semeadora (SIQUEIRA et al., 1999).

A capacidade operacional foi calculada utilizando-se a eficiência de campo de $85 \%$ para o arado de discos, $80 \%$ para a grade e $70 \%$ para a semeadura, resultando em tempos operacionais de 2,242 horas ha $^{-1}$ para a aração; 0,706 hora ha-1 para a gradagem e 0,840 hora ha $^{-1}$ para a semeadura (ASAE, 1996) citado por Furlani et al. (2004). O consumo de diesel, massa especifica de $887 \mathrm{~g} \mathrm{~L}^{-1}$ (SALVADOR et al., 2008; SALVADOR et al., 2009), foi de 29,35 $\mathrm{L} \mathrm{ha}^{-1}$ para a aração, 6,40 $\mathrm{L} \mathrm{ha}^{-1}$ para a gradagem e $11,58 \mathrm{~L} \mathrm{ha}^{-1}$ para a semeadura (SIQUEIRA et al., 1999) e para a colheita de 17,50 L ha-1, segundo Siqueira et al. (2008).

A energia dos lubrificantes e filtros foi estimada em $5 \%$ da energia do combustível, consumido em cada operação e adotou-se como índices energéticos os valores de $38,56 \mathrm{MJ} \mathrm{L}^{-1}$ para o poder calorífico do óleo diesel, 69,88 $\mathrm{MJ} \mathrm{kg}^{-1}$ para tratores e $57,61 \mathrm{MJ} \mathrm{kg}^{-1}$ para equipamentos (PIMENTEL, 1980).

Uma semana antes da semeadura da mamona foi realizada a dessecação da vegetação presente na área com o herbicida glyphosate (SL), na dose de 1,8 L do i.a. ha-1 , que apresenta $347,88 \mathrm{MJ} \mathrm{kg}^{-1}$ segundo Pimentel (1980) utilizando volume de aplicação de $250 \mathrm{~L} \mathrm{ha}^{-1}$, o equipamento utilizado para os cálculos foi um pulverizador tratorizado de barras com $12 \mathrm{~m}$ de comprimento e bicos leque 11002 espaçados de 0,50 m (MORO, 2008).

As sementes de mamona foram tratadas com fungicida carboxin-thiran (SC) (60 g do ingrediente ativo por $100 \mathrm{~kg}^{-1}$ de sementes) e inseticida thiametoxan (WG) (75 $\mathrm{g}$ do ingrediente ativo por $100 \mathrm{~kg}^{-1} \mathrm{de}$ sementes) (MORO, 2008). Os inseticidas apresentam valores energéticos de $311,08 \mathrm{MJ} \mathrm{kg}^{-1}$ e os fungicidas 209,69 $\mathrm{MJ} \mathrm{kg}^{-1}$ (PIMENTEL, 1980).

O híbrido foi semeado em linhas de $0,45 \mathrm{~m}$

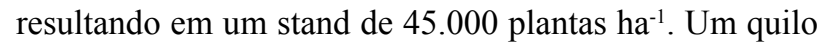
de sementes de mamona possui equivalente energético de 19,03 MJ (ALBUQUERQUE et al., 2008a).

Segundo Albuquerque et al. (2008b) e Severino et al. (2009), o peso de uma semente do híbrido Lyra foi de $0,600 \mathrm{~g}$, sendo utilizado no entanto $27 \mathrm{~kg}$ de semente ha-1 .

De acordo com a análise do solo da área utilizada como referência para o plantio, foi determinada a utilização do adubo NPK com formulação 08-28-16 $+4,5 \%$ de $\mathrm{S}+0,5 \%$ de $\mathrm{Zn}$, totalizando $250 \mathrm{~kg} \mathrm{ha}^{-1}$ do fertilizante na semeadura.

Para fabricação de adubos nitrogenados, fosfatados e potássicos são gastos $62,51 \mathrm{MJ} \mathrm{kg}^{-1}, 9,63$ $\mathrm{MJ} \mathrm{kg}^{-1}$ e 9,17 $\mathrm{MJ} \mathrm{kg}^{-1}$, respectivamente (PIMENTEL, 1980) e para o enxofre são gastos 5,52 $\mathrm{MJ} \mathrm{kg}^{-1}$ (SALLA; CABELLO, 2007). E para o micronutriente são gastos 6,32 $\mathrm{MJ} \mathrm{kg}^{-1}$ segundo Souza et al. (2008).

O controle de plantas daninhas de folhas estreitas, foi realizado com aplicação do herbicida sethoxydim (CE), na dose de $184 \mathrm{~g} \mathrm{~L}^{-1}$ de ingrediente ativo por hectare $+1 \%$ de óleo mineral, e o controle das plantas daninhas de folhas largas foi realizado com o herbicida clorimurom etílico (WG) na dosagem de $20 \mathrm{~g}$ de ingrediente ativo por hectare, em um volume de aplicação de $200 \mathrm{~L} \mathrm{ha}^{-1}$, onde os valores são de $347,88 \mathrm{MJ} \mathrm{kg}^{-1}$, para os herbicidas e de $270,82 \mathrm{MJ} \mathrm{kg}^{-1}$ ou L $\mathrm{L}^{-1}$ para os espalhantes segundo Pimentel (1980).

Devido à incidência da doença mofo cinzento (Botrytis ricini), foram feitas duas aplicações de fungicida. A primeira no início do florescimento e a segunda 20 dias após. Os produtos utilizados foram procimidona (PM), fungicida sistêmico na dose de 150 gramas de ingrediente ativo por hectare e iprodiona (PM), fungicida de contato na dosagem de $150 \mathrm{~g}$ de ingrediente ativo por hectare, segundo Pimentel (1980) os fungicidas apresentam valores de 209,69 $\mathrm{MJ} \mathrm{kg}^{-1}$.

Quando $100 \%$ das plantas apresentavam no mínimo dois racemos maduros foi realizada a dessecação, com 2,05 L de ingrediente ativo por hectare de glyphosate (SL). Essa operação foi efetuada para facilitar a colheita e para uniformizar a maturação dos frutos dos demais racemos formados.

Para o esmagamento e o refino da mamona foram gastos 22.150,00 $\mathrm{MJ} \mathrm{ha}^{-1} \mathrm{e}$ a rota utilizada para a produção de biodiesel foi à etílica (BME) com consumo de 23.820,00 $\mathrm{MJ} \mathrm{ha}^{-1}$ (ALMEIDA NETO et al., 2004). 


\section{Resultados e discussão}

Os resultados mostraram que a energia indireta (TAB. 1) utilizada na implantação e manejo da cultura da mamona foi maior para a operação de aração do solo, com $41,50 \%$, confirmando os dados obtidos por Siqueira et al. (1999), que encontraram o percentual de $43,70 \%$ da utilização de energia indireta para a aração. A operação de semeadura e colheita consumiu 25,50 e $17,10 \%$, respectivamente, da energia indireta como mostra a Tabela 1. A dessecação e a semeadura requereram menor demanda de energia indireta em razão da maior capacidade de campo.

Na Tabela 2 encontram-se os valores de energia indireta das sementes, fertilizantes e agrotóxicos. Os herbicidas acumularam 53,80\%, com 3.854,51 $\mathrm{MJ}^{\text {ha }}{ }^{-1}$ da energia indireta, próximos aos encontrados por Siqueira et al. (2008). Os nutrientes utilizados foram o nitrogênio, fósforo, potássio, enxofre, além do zinco que juntos, somaram $29,80 \%$ do gasto energético. Elevadas participações percentuais dos fertilizantes também foram descritas por Siqueira et al. (2008). O nitrogênio, dos nutrientes, foi o que apresentou maior gasto energético, com $17,50 \%$ do total. Os fungicidas e espalhante também fizeram parte dos gastos com energia indireta, e juntos apresentaram 9,40\%.

$\mathrm{Na}$ Tabela 3 os custos energéticos calculados em energia direta dos combustíveis e lubrificantes, demonstraram que o maior consumidor do combustível foi à operação de aração, sendo, portanto contrário aos resultados de Siqueira et al. (2008), que apontaram a

Tabela 1 - Conteúdo energético (energia indireta), por operação, das máquinas e equipamentos utilizados na implantação e manejo da cultura da mamona

\begin{tabular}{|c|c|c|c|c|}
\hline Operação & Máquina/equipamento & Energia $\mathrm{MJ} \mathrm{ha}^{-1}$ & Total operação MJ ha-1 & $\%$ \\
\hline \multirow{2}{*}{ Aração } & Trator & 94,76 & \multirow{2}{*}{115,54} & 41,50 \\
\hline & Arado & 20,78 & & \\
\hline \multirow{2}{*}{ Gradagem } & Trator & 19,69 & \multirow{2}{*}{25,83} & 9,30 \\
\hline & Grade & 6,14 & & \\
\hline \multirow{2}{*}{ Aplicação Fungicida } & Trator & 4,10 & \multirow{2}{*}{6,11} & 2,20 \\
\hline & Pulverizador & 2,01 & & \\
\hline \multirow{2}{*}{ Dessecações } & Trator & 8,20 & \multirow{2}{*}{12,22} & 4,40 \\
\hline & Pulverizador & 4,02 & & \\
\hline \multirow{2}{*}{ Semeadura } & Trator & 35,51 & \multirow{2}{*}{70,92} & \multirow[t]{2}{*}{25,50} \\
\hline & Semeadora & 35,41 & & \\
\hline Colheita & Colhedora & 47,80 & 47,80 & 17,10 \\
\hline Total & & & 278,42 & \\
\hline
\end{tabular}

Tabela 2 - Energia indireta nas sementes, fertilizantes e agrotóxicos e participação percentual na entrada de energia para produção de mamona

\begin{tabular}{lccc}
\hline \multicolumn{1}{c}{ Origem } & Utilização ha $^{-1}$ & Energia MJ ha $^{-1}$ & $\%$ \\
\hline Sementes & $27,00 \mathrm{~kg}$ & 513,81 & 7,20 \\
Nitrogênio & $20,00 \mathrm{~kg}$ & $1.250,20$ & 17,50 \\
Fósforo & $45,00 \mathrm{~kg}$ & 433,35 & 6,10 \\
Potássio & $40,00 \mathrm{~kg}$ & 366,80 & 5,10 \\
Enxofre & $11,25 \mathrm{~kg}$ & 71,10 & 1,00 \\
Micronutriente & $1,25 \mathrm{~kg}$ & 6,76 & 0,10 \\
Herbicidas & $11,08 \mathrm{~L}$ & $3.854,51$ & 53,80 \\
Fungicidas & $0,60 \mathrm{~L}$ & 125,81 & 1,70 \\
Espalhantes & $2,00 \mathrm{~L}$ & 541,64 & 7,50 \\
\hline \multicolumn{1}{c}{ Total } & $7.163,98$ & \\
\hline \multicolumn{2}{c}{} \\
\hline
\end{tabular}


Tabela 3 - Custo energético (energia direta) dos combustíveis e lubrificantes, nas operações utilizadas para a produção da mamona

\begin{tabular}{lccc}
\hline \multicolumn{1}{c}{ Operação } & $\mathrm{L} \mathrm{ha}^{-1}$ & Energia & $\%$ \\
\hline Dessecações & 13,00 & 526,34 & 15,50 \\
Aração & 29,35 & $1.188,33$ & 34,80 \\
Gradagem & 6,40 & 259,12 & 7,60 \\
Semeadura & 11,58 & 468,85 & 13,70 \\
Fungicidas & 6,50 & 263,17 & 7,70 \\
Colheita & 17,50 & 708,54 & 20,70 \\
\hline \multicolumn{2}{c}{ Total } & 84,33 & $3.414,35$ \\
\hline
\end{tabular}

colheita como maior consumidora, embora trabalhando com outro modelo de colhedora em função da cultura utilizada. Fernandes et al. (2008) relatam que o preparo convencional do solo foi o que promoveu maior gasto de combustíveis com 20,70 $\mathrm{L} \mathrm{ha}^{-1}$, valores bem próximos aos encontrados nesse trabalho.

Deve ser considerado que no ciclo da cultura foram realizadas duas dessecações, uma na instalação e outra para a colheita da cultura, totalizando $526,34 \mathrm{MJ} \mathrm{ha}^{-1} \mathrm{com}$ combustíveis. No manejo do solo a aração e a gradagem foi realizada conforme necessidade de manejo do solo, sendo atividade consumidora de $42,40 \%$ de energia direta para combustíveis e lubrificantes. Já a semeadura apresentou gasto de $13,70 \%$ o equivalente a $11,58 \mathrm{~L} \mathrm{ha}^{-1}$, portanto gasto menor ao encontrado por Siqueira et al. (1999) e Siqueira et al. (2008), haja vista, que as semeadoras tem diferentes regulagens e diferentes velocidades, variando conforme a cultura, mas semelhantes aos resultados encontrados por Bortolotto et al. (2006) em determinadas marchas de trabalho para a semeadura da soja.

Os fungicidas utilizados no controle da doença mofo cinzento apresentaram um gasto, nas operações, de combustíveis e lubrificantes de $6,50 \mathrm{~L} \mathrm{ha}^{-1}$, totalizando $7,70 \%$ do percentual de energia direta.
Os custos energéticos totais da implantação e manejo da cultura da mamona, estão representados na Tabela 4, mostrando que a maior participação percentual é no processamento e produção industrial. Para extração do óleo e a posterior transformação em biodiesel, utilizou-se aproximadamente $80,90 \%$ do total de entradas de energia, sendo $38,99 \%$ gastos para o esmagamento das sementes e refino do óleo e $41,91 \%$ dos gastos para a produção de biodiesel, estando de acordo com o resultados relatados por Siqueira et al. (2008) para a cultura do nabo forrageiro, embora em valores percentuais menores.

Já para a mão-de-obra utilizada para a cultura da mamona, consumiu-se 3,81 $\mathrm{MJ} \mathrm{ha}^{-1}$, com valor percentual desprezível. A mão-de-obra sempre teve baixa participação percentual nas saídas de energia, como também demonstrado por Siqueira et al. (2008). Já Campos et al. (2009), relatam que o trabalho humano contribuiu com $0,41 \%$ do custo energético.

Para o custo energético no processo de produção agrícola, que totalizou $19,10 \%$ do total, os maiores usos foram estabelecidos para os agrotóxicos e para os combustíveis e lubrificantes com 8,00 e 6,00\%, respectivamente. $\mathrm{O}$ que comprovam os dados encontrados por Melo et al. (2007) em produção de milho e soja no

Tabela 4 - Custo energético total (entradas de energia), para a produção e manejo de mamona

\begin{tabular}{lcc}
\hline \multicolumn{1}{c}{ Origem } & Energia $\left(\mathrm{MJ} \mathrm{ha}^{-1}\right)$ & $\%$ \\
\hline Máquinas e equipamentos & 278,42 & 0,50 \\
Fertilizantes & $2.128,21$ & 3,70 \\
Sementes & 513,81 & 0,90 \\
Agrotóxicos & $4.521,96$ & 8,00 \\
Mão-de-obra & 3,81 & 0,00 \\
Combustíveis e lubrificantes & $3.414,35$ & 6,00 \\
Esmagamento e refino & $22.150,00$ & 38,99 \\
Produção biodiesel & $23.820,00$ & 41,91 \\
\hline \multicolumn{1}{c}{ Total } & $56.830,56$ & \\
\hline
\end{tabular}


estado do Paraná, que obtiveram gastos de $6,38 \%$ para combustíveis e lubrificantes na cultura da soja e de 4,46 para a cultura do milho.

$\mathrm{Na}$ Tabela 5, se observa a energia produzida pela parte aérea e pela produção de grãos. Na biomassa seca, o produto do cálculo da parte aérea pelo seu poder calorífico, correspondeu a $63,41 \%$ do total, que assim como Siqueira et al. (2008), mostra que além de melhorar as características do solo, pode permitir uma maior reciclagem de nutrientes, implicando em uma menor utilização de fertilizantes no decorrer dos anos de cultivo. A produção de grãos de mamona representou $36,59 \%$ do total de saída de energia.

Tabela 5 - Produção de energia (saídas) pelos resíduos e grãos de mamona

\begin{tabular}{cccc}
\hline Energia & $\mathrm{J} \mathrm{g}^{-1}$ & $\mathrm{MJ} \mathrm{ha}^{-1}$ & $\%$ \\
\hline Grãos & $19.030,00$ & $26.640,00$ & 36,59 \\
Resíduos & $17.000,00$ & $46.170,00$ & 63,41 \\
\hline Total & & $72.810,00$ & \\
\hline
\end{tabular}

As variáveis de eficiência energética da produção da cultura da mamona se encontram a tabela 6 , onde para a produção de $1,00 \mathrm{~kg}$ de biomassa foi necessária a utilização de $3.998,73 \mathrm{~kJ}$ de energia, e para a produção de $1,00 \mathrm{~kg}$ de grãos de mamona foram necessários 7.757,54 kJ de energia, valor esse superior ao encontrado por Siqueira et al. (2008) para a cultura do nabo forrageiro, por Hetz e Martinez (1998) para a cultura do girassol e da soja com $5.978,00 \mathrm{~kJ} \mathrm{~kg}^{-1}$ e $2.817,00 \mathrm{~kJ} \mathrm{~kg}^{-1}$ de energia consumida respectivamente.

Para a produção de 1 litro de óleo e 1 litro de biodiesel de mamona foram gastos respectivamente $13.474,64$ e $70.509,00 \mathrm{~kJ}$ de energia.

As relações de saída/entrada de grãos, resíduos e de grãos + resíduos encontradas foram de 0,$47 ; 0,81$ e 1,28 respectivamente, mostrando a importância de se considerar a biomassa em um balanço energético, como já relatado por Siqueira et al. (2008) para a cultura do nabo forrageiro. A conversão energética foi de 1,28, valor inferior ao encontrado por Siqueira et al. (2008) para a cultura do nabo forrageiro $(8,44)$ e por Gazzoni et al. (2005) para a cultura da soja 3,95 e de 2,37 para a cultura do girassol.

A produção de óleo de mamona foi de $806 \mathrm{~L} \mathrm{ha}^{-1}$. O ganho de energia foi de aproximadamente $15.983,44 \mathrm{MJ} \mathrm{ha}^{-1}$, correspondendo, segundo Siqueira et al. (2008) ao valor de 413,98 litros de óleo diesel.

Tabelas 6 - Variáveis de eficiência energética para a produção de mamona

\begin{tabular}{|c|c|}
\hline Indicador & Unidade \\
\hline \multicolumn{2}{|l|}{ Fase agrícola } \\
\hline Saída de energia (grãos) & $26.64 \mathrm{MJ} \mathrm{ha}^{-1}$ \\
\hline Saída de energia (resíduos) & 46.17 $\mathrm{MJ} \mathrm{ha}^{-1}$ \\
\hline Saída total de energia & $72.81 \mathrm{MJ} \mathrm{ha}^{-1}$ \\
\hline Entradas de energia na fase agrícola & $10.860,56 \mathrm{MJ} \mathrm{ha}^{-1}$ \\
\hline Produção de óleo & $806 \mathrm{~L} \mathrm{ha}^{-1}$ \\
\hline Litros óleo de mamona (saída)/litros óleo diesel (entrada) & 9,56 \\
\hline Relação saída/entrada (grãos) & 0,47 \\
\hline Relação saída/entrada (resíduos) & 0,81 \\
\hline Relação saída/entrada (grãos + resíduos) & 1,28 \\
\hline Energia para a produção de $01 \mathrm{~kg}$ biomassa & $3.998,73 \mathrm{~kJ}$ \\
\hline Energia para a produção de $01 \mathrm{~kg}$ de grãos & $7.757,54 \mathrm{~kJ}$ \\
\hline Energia para a produção de $01 \mathrm{~L}$ de óleo & $13.474,64 \mathrm{~kJ}$ \\
\hline \multicolumn{2}{|l|}{ Fase agrícola + industrial } \\
\hline Entradas de energia na fase industrial & 45.970,00 $\mathrm{MJ} \mathrm{ha}^{-1}$ \\
\hline Entrada total de energia & $56.830,56 \mathrm{MJ} \mathrm{ha}^{-1}$ \\
\hline Ganho líquido de energia & $15.983,44 \mathrm{MJ} \mathrm{ha}^{-1}$ \\
\hline Energia para produção 01 litro biodiesel & $70.509,00 \mathrm{~kJ}$ \\
\hline
\end{tabular}




\section{Conclusões}

1. Os dados relacionados a consumo e eficiência energética constituem poderosas ferramentas para diagnosticar problemas relacionados à sustentabilidade de sistemas produtivos agrícolas. Porém o setor ainda carece de estudos que contribuiriam para o levantamento de dados e coeficientes energéticos mais específicos;

2. A cultura da cultura da mamona, em função do balanço de energia, foi considerada eficiente, permitiu ganho energético de 15.983,44 $\mathrm{MJ} \mathrm{ha}^{-1}$, equivalente a aproximadamente 415 litros de óleo diesel;

3. A biomassa dos resíduos representou uma grande fonte de matéria orgânica, com aproximadamente $2 \mathrm{t} \mathrm{ha}^{-1}$.

\section{Referências}

ALBUQUERQUE, F. A. et al. Análise energética do consórcio manpna com amendoim. In: CONGRESSO BRASILEIRO DE MAMONA, 6., 2008, Salvador. Anais... Salvador: SEAGRI: Embrapa Algodão, 2008a. 1 CD-ROM.

ALBUQUERQUE, W. G. et al. Variação no percentual de tegumento em relação ao peso da semente de dez genótipos de mamoneira. In: CONGRESSO BRASILEIRO DE MAMONA, 5., 2008, Salvador. Anais... Salvador: SEAGRI: Embrapa Algodão, 2008b. 1 CD-ROM.

ALMEIDA NETO, J. A. et al. Balanço Energético de Ésteres Metílicos Etílicos de Óleo de Mamona. In: CONGRESSO BRASILEIRQ DE MAMONA, 7., 2004, Campina Grande. Anais eletrônicos... Campina Grande, 2004. Disponível em: $<\mathrm{http}: / /$ www.uesc.br/ ecodiesel/tra_completos/122Balan\%E7o_ Energ\%E9tico_Almeida.pdf>. Acesso em: 29 out. 2009.

BORTQLOTTO, V. C.; PINHEIRO NETO, R.; BORTOLOTTO, M. C. Deplanda energética de uma semeadora-adubadora para soja sob diferentes velocidades de deslocamento e coberturas do solo. Revista Engenharia Agrícola, v. 26, n. 01, p. 122-130, 2006.

CAMPOS, A. T.; CAMPOS, A. T. Balanços energéticos agropectários: uma importante ferramenta como indicativo de sustentabilidade de agroecossistemas. Revista do Centro de Ciência Rural, v. 34, n. 06, p. 1977-1985, 2004.

CAMPOS, A. T. et al. Análise energética da produção de soja em sistema plantio direto. Global Science and Technology, v. 02, n.02, p. 38 - 44, 2009.

CORRÊA, M. L. P.; TÁVORA, F. J. A. F.; PITOMPEIRA, J. B. Compprtamento de cultivares de mamona em plantio consorciadas com caupi e sorgo granífero. Revista Ciência Agronômica, v. 37, n. 02, p. 200-207, 2006.

COSTA, F. X. et al. Efeito do lixo orgânico e torta de mamona nas caracterígicas de crescimento da mamoneira (Ricinus communis L.C. Revista Engenharia Ambiental, v. 06, n. 01, p. 259-268, 2009.
FERUNDES, H. C.; SILVEIRA, J. C. M. da.; RINALDI, P. C. N. A aliação do custo energético de diferentes operações agrícolas mecanizadas. Revista Ciência e Agrotecnologia, v. 32, n. 05, p. 1582-1587, 2008.

FURL\{NI, C. E. A. et al. Desempenho operacional de uma semeadpra-athibadora de precisão, Em função do preparo do solo e to thanejo da cobertura de inverno. Revista Engenharia Agrícola, v. 24, n. 02, p. 388-395, 2004.

GAZZфNI, D. L.; FELICI, P. H. N; CORONATO, R. M. S.; RALISCH, R. Balanço energético das culturas de soja e girassol para preduçådde biodiesel. Biomassa \& Energia, v. 02, n. 04, p. 259-265. 2005.

HEXZ, E.H. MARTINEZ, F. V. Requerimentos energéticos para la ploduccion de maravilla (Helianthus annuus) en la provincia de Nuble. Agro-Ciencia, v. 04, n. 02, p. 141-146, 1998.

MACIEL, C. D. G. et al. Seletividade de herbicidas em cultivares de mamonar. Revista Brasileira de Oleaginosas e Fibrosas, v. 11) n. 01, p. $47-54,2007$.

MAIA, A. C. S. et al. Estudo da Adição do Biodiesel de Mamona ao Óreo Dies $\notin 1$ Mineral sobre a Massa Específica e Viscosidade Cinemática. n: CONGRESSO DA REDE BRASILEIRA DE TECNOL OGIA DE BIODIESEL, 2., 2007, Brasília. Anais eletrôn cos... Brasília: ABIPTI, 2007. Disponível em: $<$ www.biodiesel.gov.br/docs/congresso2006 /agricultura/ balancoenergetico.pdf>. Acesso em: 08 mai. 2010.

MEGO, p. de. et al. Balanço energético do sistema de produção de soja e milho em uma propriedade agrícola do Oeste do Paraná. Acta Scientiarum Agronomy, v. 29, n. 02, p. 173-178, 2007.

MORO, E. Manejo da adubação nitrogenada em híbridos de mamona de porte baixo cultivados na safra e na safrinha em sistema plantio direto. 2008. 133 f. Dissertação (Mestrado em Fitotecnia) - Universidade Estadual Paulista "Júlio de Mesquita Filho", Botucatu.

PIMENTEL, D; BURGESS, M. Energy inputs in corn production. In: PIMENTEL D. (Ed.). Handbook of energy utilization in agriculture. Bofa Răton: CRC Press, 1980. p. 67-84.

PLÁ, J. A. Perspectivas do biodiesel no Brasil. Indicadores Econômicog FEE, v. 30, n. 02, p. 179-190, 2002.

RANESES, A. R. et al. Potential biodiesel markets and their econotmic effeets on the agricultural sector of the United States. Industrial Crops and Products, v. 09, n. 02, p. 151 $-162,1999$.

SALlA, $D$. A.; CABELlO, C. Análise de desempenho energétic dos cultivos da mandioca, cana-de-çúcar e milho em funçåo da extraça/exportação de macronutrientes para produçao sustentável de etahol. In: CONGRESSO BRASILEIRO DA MANDIOCA, 4., 2007, Paranavaí. Anais eletrônicos... Paranavaí, 2007. Disponível em: <http://www.abam.com.br/congresso/ 38\%20Diones\%20assis\%20salla.pdf>. Acesso em: 01 dez. 2009.

SALVADOR, N; BENEZ, S. H.; MION, R. L. Consumo de combustível pa operação de subsolagem realizada antes e depois de dierentes sistemas de preparo periódico do solo. Revista Engenharia Agrícola, v. 28, n. 02, p. 256-262, 2008. 
SALVADOR, N.; MION, R. L.; BENEZ, S. H. Consumo de combistíverem diferentes sistemas de preparo periódico realizacos antes e depois da operação de subsolagem. Revista Ciência e Ağrotecnologia, v. 33, n. 03, p. 870-874, 2009.

SANTOS, H. P. et al. Efeito de práticas culturais na conversão e no balanço energéticos. Bragantia, v. 66, n. 02, p. 299-306, 2007.

SEVERINO, L. S. et al. Variabilidade no percentual de tegumento da semente de mamona e sua importância para o melhoramento. Revista Ciência Agronồmica, v. 40, n. 01, p. 94-98, 2009.

SIQUEIRA, R.; GAMERO, C. A.; BOLLER, W. Balanço de energia na implantaçãoce manejo de plantas de cobertura do solo. Revista Engenharia Agrícola, v. 19, n. 01, p. 80-89, 1999.
SIQUEIRA, R.; GAMERO, C. A.; BOLLER, W. . Energetic balance from bibdiesel production of oilseed radish (Raphanus sativus L.). (In: INTERNACIONAL CONFERENCE OF AGRICULTU ENGINEERING, 12., 2008, Foz do Iguaçu. Anais... Foz do Iguaçu. 1 CD-ROM.

SOUZA, J. L. de. etal. Balanço e análise da sustentabilidade energética na produtã̃o orgânica de hortaliças. Revista Horticultura Brasileira, v. 26, n. 04, p. 433-440, 2008.

URQUIAGA, S.; AL NES, B..R.; BOODEY, R.M. Produção de biocombustíveis: a questão do balanço energético. Revista de Política Agrícola, v. 14, n. 01, p. 42-46, 2005. 